\title{
Analytic Hierarchy Process-based Youth Basketball Reserve Personnel Training Mode Research
}

\author{
Yongqiang $\mathrm{Li}^{*}$ \\ Institute of Physical Education, Jiangsu Normal University, Xuzhou 221116, Jiangsu, China
}

\begin{abstract}
Basketball is constantly booming with China's material and cultural levels development. And basketball reserve personnel quantity and quality stand for a nation basketball level. On the current all countries basketball levels rapidly development situation in the world, cultivation of basketball reserve personnel has become an indispensible condition to be in an invincible position in intense basketball. The paper makes specific analysis of present youth basketball players' status, and trainers' training work experience, performances in the games, gets present youth basketball reserve personnel cultivation existing problems, and provides corresponding opinions for the problems. Utilize mathematics analytic hierarchy process method, establish youth basketball reserve personnel training mode AHP model, by comparing mode of combination of sports and education, backup talent base model, youth club training mode weights, it gets mode that is most suitable for training China's youth basketball reserve personnel. By analysis, it gets conclusion that all trainer, training field, training equipment, educational investment and else have certain impacts on China's youth basketball reserve personnel training mode, mode of combination of sports and education has the largest weight, is the most suitable mode for youth reserve personnel cultivation.
\end{abstract}

Keywords: Analytic hierarchy process, combination of sports and education, reserve personnel, youth basketball.

\section{INTRODUCTION}

With rapid development of world basketball level, China's basketball level has also certain improvements, but from the perspective of recent years' men's basketball performances in Olympic Games and world championships, China's basketball level is still not going well. To let China's basketball to impact on world basketball power, we should focus on basketball reserve personnel training. By far, many scholars have researched on China's basketball reserve personnel cultivation [1-4].

In 2013, Ma Guo-Ming in the article "Jihua City youth basketball reserve personnel training mode study", he researched on foreign basketball developed countries' reserve personnel training and meanwhile studied China's basketball reserve personnel training, by comparing, he found deficiency in China's basketball reserve personnel training aspect, and put forward valuable suggestions on future China's youth basketball reserve personnel training [5-7]. In 2012, Niu Yun-Fei in the article "Analyze main factors affecting youth basketball players' training effects", by analyzing psychological factors, simulater, scientific physical quality training and other factors influences on youth basketball players' training effects, he got conclusions that upmost factor affected youth basketball players' training effects was psychological factor, trainers should lay emphasis on cultivating players' psychological factors [8-10].
In 2008, Chai Jian-She and Zhang Jian-Feng in the article "Research on youth basketball talents training and development mode of Chinese characteristics", he adopted multiple methods to study and analyze China's youth basketball talents training mode, analytic result indicated China's youth basketball talents training development mode had many problems, and put forward corresponding reform measures for them to make contributions to future youth basketball talents training and development.

The paper makes comprehensive analysis of youth basketball reserve personnel training status, and puts forward corresponding improvement suggestions for youth reserve personnel training development. On this basis, it utilizes analytic hierarchy process method, establishes model regarding youth basketball reserve personnel training mode, by comparing weights, it gets conclusion that training mode of combination of sports and education is most suitable to China's youth basketball reserve personnel training.

\section{CHINESE YOUTH BASKETBALL RESERVE PER- SONNEL TRAINING STATUS}

Youth is the future of Chinese sports, and reserve personnel is an important guarantee to sports development, therefore, abundant level of youth basketball reserve personnel directly decides Chinese basketball development level. By far, Chinese youth basketball's reserve personnel training has become a concern of people.

The foundation of youth basketball reserve personnel is athlete, and athlete is also an important part of a complete team composition. Therefore, the key factor that affects Chi- 
Table 1. Chinese youth basketball reserve personnel basic information statistics table.

\begin{tabular}{|c|c|c|c|c|c|c|c|c|}
\hline \multirow{2}{*}{ Type } & \multicolumn{2}{|c|}{ Height } & \multicolumn{2}{c|}{ Age } & \multicolumn{2}{c|}{ Training Age } & \multicolumn{2}{c|}{ The Highest Height } \\
\cline { 2 - 9 } & Man & Woman & Man & Woman & Man & Woman & Man & Woman \\
\hline \hline Youth basketball training base & 1.85 & 1.68 & 16.2 & 15.0 & 2.52 & 2.18 & 1.91 & 1.8 \\
\hline Basketball experimental school & 1.87 & 1.73 & 15.9 & 14.9 & 2.61 & 2.32 & 1.96 & 1.83 \\
\hline Amateur sports school & 1.90 & 1.79 & 16.8 & 15.6 & 3.98 & 3.41 & 2.02 & 1.89 \\
\hline Basketball school & 1.90 & 1.78 & 15.1 & 14.8 & 2.17 & 1.71 & 1.99 & 1.85 \\
\hline
\end{tabular}

Table 2. Athletes motivation investigation table.

\begin{tabular}{|c|c|c|c|c|}
\hline Reason & Case One & Case Two & Case Three & Syn-Position \\
\hline \hline Become high-level athletes & 16.2 & 14.6 & 20.4 & 5 \\
\hline Body building & 3.1 & 5.2 & 30.3 & 2 \\
\hline University entrance exam & 26.3 & 29.8 & 28.1 & 1 \\
\hline Win honor for school & 31.8 & 26.7 & 9.8 & 3 \\
\hline Hobbies and interests & 18.8 & 21.3 & 1.4 & 7 \\
\hline Win a scholarship & 0.9 & 0.3 & 0.5 & 6 \\
\hline Family decision & 1.4 & 1.4 & 0 & 8 \\
\hline Else & 0.5 & 0.5 & \\
\hline
\end{tabular}

nese youth basketball reserve personnel level is the quality of athletes.

By Table 1, we can see that Chinese youth basketball reserve personnel height relative looks good, male athlete highest height is 2.02 meters, female athlete highest height is 1.89 meter. Basketball reserve personnel is relative young, it is helpful for Chinese basketball development, but from the perspective of training age, Chinese youth basketball reserve personnel training age is averagely two to three years, thereupon, training age is shorter, which indicates Chinese youth reserve personnel starts late, and emphasis that lays on basketball reserve personnel is not enough. Chinese government should focus on youth reserve personnel training.

Many reasons for youth entering into basketball team and becoming athletes, not all athletes join the basketball team because of fondness on basketball and would like to make contribution to homeland basketball. Table $\mathbf{2}$ is investigation on Chinese youth athletes' motivation.

From Table 2, it is clear that athletes main motivations are winning honor for school the university entrance exam, secondly are hobbies and interests becoming high-level athletes, others in order are body building family decision winning a scholarship else.

Trainers are reserve personnel training guides. Trainers' training work experience, previous seasons can reflect trainers' experience is abundant or not. In the following, we analyze Chinese trainers' training work experiences and performances:
According to Tables $\mathbf{3}$ and $\mathbf{4}$ data, it is clear that trainers' guiding years as below six years are the most that account for $40 \%$, while below 20 years are the least that only account for $5 \%$, from the perspective of trainers' guiding performance, top three in nationwide game account for $8 \%$, top three in provincial level game account for $13 \%$, top three in city level game account for $28 \%$, thereupon, it analyzes that Chinese trainers' guiding years are shorter, obtained performances are most in provincial and city level games, Chinese basketball trainers are to be improved in the aspect of instructing experience.

\section{YOUTH BASKETBALL RESERVE PERSONNEL TRAINING MODE INFLUENTIAL ANALYTIC HI- ERARCHY PROCESS MODEL}

Basketball reserve personnel training mode suffers numerous factors influences, such as trainers, training fields, training equipment, educational investment and else. The paper establishes analytic hierarchy process model to quantize basketball reserve personnel training mode orientation, by establishing target layer, criterion layer and scheme layer relationships, finally it gets most suitable Chinese youth basketball reserve personnel training mode in future.

AHP is making classification of included factors according to problems requirements and attributes, generally it divides them into target layer, criterion layer and scheme layer, so that forms into a hierarchical structure, adopts paired mutual comparison way to the same layer each factor so that defines every layer weight with respect to previous layer 
Table 3. Trainers guided years 60 person.

\begin{tabular}{|c|c|c|}
\hline Trainers' Guided Years & Number of People & Percentage\% \\
\hline \hline Below 20 years & 3 & 25 \\
\hline Below 15 years & 6 & 18 \\
\hline Below 10 years & 11 & 40 \\
\hline Below 6 years & 24 & 27 \\
\hline Below 3 years & 16 & 25 \\
\hline
\end{tabular}

Table 4. Trainers' guiding performance 60 person.

\begin{tabular}{|c|c|c|}
\hline Best Performance Guided Teams' Obtained & Number of People & Percentage\% \\
\hline \hline A Nationwide game & 12 & 80 \\
\hline a Rank 1-3 & 5 & 12 \\
\hline b Rank 4-6 & 7 & 32 \\
\hline B Provincial level game & 19 & 13 \\
\hline a Rank 1-3 & 8 & 18 \\
\hline b Rank 4-6 & 11 & 48 \\
\hline C City level game & 29 & 28 \\
\hline a Rank 1-3 & 17 & 20 \\
\hline b Rank 4-6 & 12 & \\
\hline
\end{tabular}

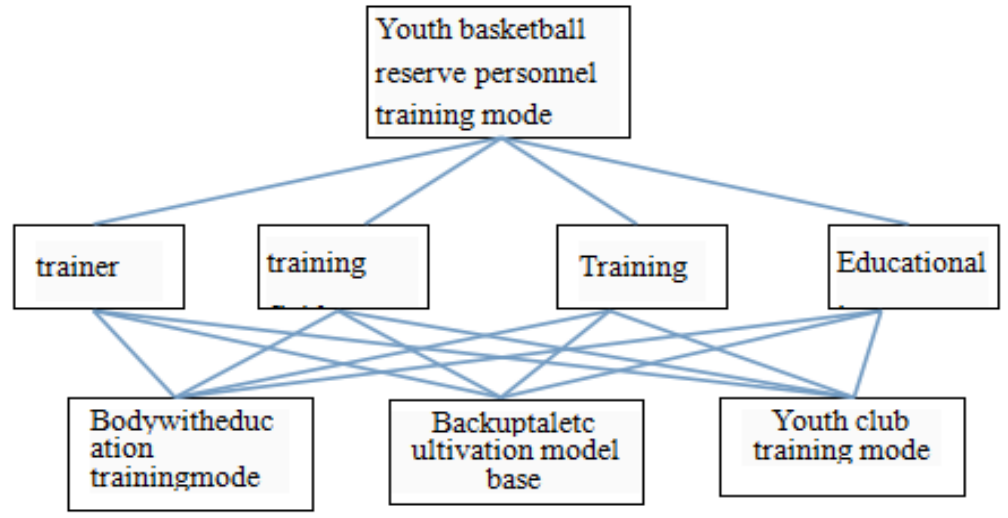

Fig. (1). Youth basketball reserve personnel training mode of hierarchical analysis.

target. By analyzing every layer, finally arrange each factor of target layer, criterion layer and scheme layer, the arrangement is ranking according to its importance relative total target. Its main features are reasonable combining qualitative and quantitative decision-making so that layering and quantify decision-making process, as Fig. (1).

Target layer: Youth basketball reserve personnel training mode

Criterion layer: Scheme influence factors, is trainer, is training field, is training equipment, is educational investment
Scheme layer: is training mode of combination of sports and education, is backup talents base training mode, is youth club training mode

\subsection{Trainer}

Trainer plays a leading role in basketball reserve personnel training mode, is the key factor in training reserve personnel. Trainers' age structure, education background, job title structure, sports experience, instructing level and experiences and else, all of them affect Chinese youth basketball reserve personnel training mode. 
Table 5. 1 9 Scale descriptions.

\begin{tabular}{|c|c|}
\hline Scale $a_{i j}$ & Description \\
\hline 1 & factor $\mathrm{i}$ and factor $\mathrm{j}$ have equal importance \\
\hline 3 & factor $\mathrm{i}$ is slightly more important than factor $\mathrm{j}$ \\
\hline 5 & factor $\mathrm{i}$ is relative more important than factor $\mathrm{j}$ \\
\hline 7 & factor $\mathrm{i}$ is extremely more important than factor $\mathrm{j}$ \\
\hline 9 & factor $\mathrm{i}$ is absolute more important than factor $\mathrm{j}$ \\
\hline $2,4,6,8$ & Indicates middle state corresponding scale value of above judgments \\
\hline Reciprocal of above each numerical value & $\begin{array}{r}\text { If indicator } i \text { compares with indicator } j \text {, relative importance use one numerical scale of above, then indica- } \\
\text { tor } j \text { and indicator } i \text { relative importance uses above numerical values' reciprocal scale }\end{array}$ \\
\hline
\end{tabular}

\subsection{Training Field}

Training field is an indispensible space to organize youth basketball training. By far, as number of people that love Chinese youth basketball has increased, in case that basketball fields are limited, short supply occurs. In order to guarantee youth training, trainers will consider multiple training modes.

\subsection{Training Equipment}

Sound training equipment is the most basic material guarantee for athletes' training games. If training equipment is simple and crude, it not only affects trainers' passing on techniques, but also affects athletes acquiring knowledge, and then further affects reserve personnel training mode.

\subsection{Educational Investment}

Educational investment is economic foundation and material guarantee for youth reserve personnel training mode, it directly affects basketball reserve personnel training mode development.

Construct paired comparison matrix is making paired comparison of elements, uses matrix form to express every layer each element important degree to its previous layer element, here introduces operational researcher proposed $1 \sim 9$ ratio scale Table 5 .

According to above scale table, set judgment matrix to be $A$ as:

$$
A=\left(\begin{array}{cccc}
1 & 2 & 4 & 3 \\
\frac{1}{2} & 1 & 3 & 3 \\
\frac{1}{4} & \frac{1}{3} & 1 & 1 \\
\frac{1}{3} & \frac{1}{3} & 1 & 1
\end{array}\right)
$$

Obviously, $A$ is positive reciprocal matrix.

1 Consistency matrix definition and attribute

a. Consistency matrix definition: positive reciprocal matrix that meets $a_{i j} * a_{j k}=a_{i k}, i, j=1,2, \cdots, n$ is consistency matrix. Such as:

$$
A=\left(\begin{array}{cccc}
\frac{w_{1}}{w_{1}} & \frac{w_{1}}{w_{2}} & \cdots & \frac{w_{1}}{w_{n}} \\
\frac{w_{2}}{w_{1}} & \frac{w_{2}}{w_{2}} & \cdots & \frac{w_{2}}{w_{n}} \\
\vdots & \vdots & \ddots & \vdots \\
\frac{w_{n}}{w_{1}} & \frac{w_{n}}{w_{2}} & \cdots & \frac{w_{n}}{w_{n}}
\end{array}\right)
$$

b. Consistency matrix attribute: matrix $A$ order is 1, $A$ unique nonzero feature root is $n$. Matrix $A$ any column vector is feature vector that corresponds to $n$. Matrix $A$ normalization feature vector can be used as weight vector.

However, in above constructed comparison matrix

$$
A=\left(\begin{array}{cccc}
1 & 2 & 4 & 3 \\
\frac{1}{2} & 1 & 3 & 3 \\
\frac{1}{4} & \frac{1}{3} & 1 & 1 \\
\frac{1}{3} & \frac{1}{3} & 1 & 1
\end{array}\right)
$$

Because $a_{12}=\frac{C_{1}}{C_{2}}=2, a_{13}=\frac{C_{1}}{C_{3}}=4$, it can get $a_{23}=\frac{C_{2}}{C_{3}}=2$

But actually $a_{23}=3$. So $A$ is not consistency matrix. In general, to inconsistent (but in permissible range) paired comparison matrix $A$, it suggests to use feature vector that corresponds to maximum feature root $\lambda$ as weight vector.

2 Consistency test

Consistency indicator: $C I=\frac{\lambda_{\max }-n}{n-1}$

Among them, $\lambda_{\max }$ is maximum feature value of comparison matrix, $\mathrm{n}$ is comparison matrix order number. $n$ 
Order positive reciprocal matrix maximum feature $\operatorname{root} \lambda \geq n$, and when $\lambda=n$, it is consistency matrix.

CI value gets smaller, judgment matrix will get closer to fully consistency. On the contrary, judgment matrix deflect fully consistency will be bigger.

Random consistency indicator: randomly generate multiple matrix, add every matrix consistency indicator and get average value, it gets $R I$, as Table 6 .

Consistency ratio: if $C R=\frac{C I}{R I}<0.1$, constructed paired comparison matrix $A$ passes consistency test.

By calculating, it can get paired comparison matrix $A$ maximum feature value $\lambda_{\max }=4.153, R I=0.79$

By consistency indicator $C I=\frac{\lambda_{\max }-n}{n-1}$, input data it can calculate and get:
$C I=\frac{4.153-4}{4-1}=0.051$

And by consistency ratio $C R=\frac{C I}{R I}=\frac{0.051}{0.79}=0.065<0.1$, so constructed paired comparison matrix $A$ passes consistency test.

Constructed all scheme layer judgment matrix with respect to different criterions are as Table 7-10.

Calculate weight vector

For paired comparison matrix:

$A=\left(\begin{array}{cccc}1 & 2 & 4 & 3 \\ \frac{1}{2} & 1 & 3 & 3 \\ \frac{1}{4} & \frac{1}{3} & 1 & 1 \\ \frac{1}{3} & \frac{1}{3} & 1 & 1\end{array}\right)$

Table 6 Random consistency indicator.

\begin{tabular}{|l|l|l|l|l|c|c|c|c|c|c|c|}
\hline$n$ & 1 & 2 & 3 & 4 & 5 & 6 & 7 & 8 & 9 & 10 & 11 \\
\hline$R I$ & 0 & 0 & 0.58 & 0.90 & 1.12 & 1.24 & 1.32 & 1.41 & 1.45 & 1.49 & 1.51 \\
\hline
\end{tabular}

Table 7 Criterion layer judgment matrix B1.

\begin{tabular}{|c|c|c|c|}
\hline$C_{1}$ & $A_{1}$ & $A_{2}$ & $A_{3}$ \\
\hline \hline$A_{1}$ & 1 & 1 & $1 / 3$ \\
\hline$A_{2}$ & 1 & 1 & $1 / 3$ \\
\hline$A_{3}$ & 3 & 3 & 1 \\
\hline
\end{tabular}

Table 8 Criterion layer judgment matrix B2.

\begin{tabular}{|c|c|c|c|}
\hline$c_{2}$ & $A_{1}$ & $A_{2}$ & $A_{3}$ \\
\hline \hline$A_{1}$ & 1 & 5 & 5 \\
\hline$A_{2}$ & $1 / 5$ & 1 & 5 \\
\hline$A_{3}$ & $1 / 5$ & $1 / 5$ & 1 \\
\hline
\end{tabular}

Table 9 Criterion layer judgment matrix B3.

\begin{tabular}{|c|c|c|c|}
\hline$c_{3}$ & $A_{1}$ & $A_{2}$ & $A_{3}$ \\
\hline \hline$A_{1}$ & 1 & 5 & 8 \\
\hline$A_{2}$ & $1 / 5$ & 1 & 5 \\
\hline$A_{3}$ & $1 / 8$ & $1 / 5$ & 1 \\
\hline
\end{tabular}


Table 10 Criterion layer judgment matrix B4.

\begin{tabular}{|c|c|c|c|}
\hline$c_{4}$ & $A_{1}$ & $A_{2}$ & $A_{3}$ \\
\hline \hline$A_{1}$ & 1 & 5 & 8 \\
\hline$A_{2}$ & $1 / 5$ & 1 & 5 \\
\hline$A_{3}$ & $1 / 8$ & $1 / 5$ & 1 \\
\hline
\end{tabular}

At first proceed with following processing:

$\stackrel{\text { Column vector normalization }}{\longrightarrow}\left(\begin{array}{cccc}0.829 & 0.962 & 0.521 & 0.521 \\ 0.275 & 0.321 & 0.84 & 0.84 \\ 0.275 & 0.061 & 0.165 & 0.165 \\ 0.275 & 0.061 & 0.165 & 0.165\end{array}\right)$
$\stackrel{\text { According to the row sum }}{\longrightarrow}\left(\begin{array}{l}2.799 \\ 2.265 \\ 0.683 \\ 0.683\end{array}\right) \stackrel{\text { The normalized }}{\longrightarrow}\left(\begin{array}{l}0.711 \\ 0.568 \\ 0.172 \\ 0.172\end{array}\right)=W^{0}$

Then, by $A \times W^{0}$ it further solves $\lambda^{0}{ }_{\max }=4.241$.

Similarly, it can solve criterion layer judgment matrix maximum feature value and weight is as following:

$$
\begin{aligned}
& \lambda_{\text {max }}^{1}=3.62, W_{1}=\left(\begin{array}{l}
0.243 \\
0.243 \\
0.511
\end{array}\right) ; \lambda_{\text {max }}^{2}=3.27, W_{2}=\left(\begin{array}{l}
0.656 \\
0.254 \\
0.091
\end{array}\right) ; \\
& \lambda_{\text {max }}^{3}=3.33, W_{1}=\left(\begin{array}{l}
0.651 \\
0.214 \\
0.151
\end{array}\right) ; \lambda_{\text {max }}^{4}=3.33, W_{4}=\left(\begin{array}{l}
0.651 \\
0.214 \\
0.151
\end{array}\right)
\end{aligned}
$$

And utilize above principles judgment, it gets that all pass consistency test.

By $W^{1}=\left(W_{1}, W_{2}, W_{3}, W_{4}\right)$, and $W=W^{1} \times W^{0}$ it can calculate and get :

$$
W=\left(\begin{array}{l}
0.539 \\
0.189 \\
0.272
\end{array}\right)
$$

By above combination weight calculation result, it analyzes that mode of combination of sports and education accounts for $53.9 \%$, reserve personnel base training mode accounts for $18.9 \%$, youth club cultivation mode accounts for $27.2 \%$. Then it can get conclusion that mode of combination of sports and education is most suitable to Chinese youth basketball reserve personnel training.

\section{CONCLUSION}

At first, the paper makes comprehensive analysis of youth basketball reserve personnel training status, it finds that presently China has deficiency in youth basketball re- serve personnel training, and puts forward opinions. By making specific analysis of Chinese youth sports status and trainers' working years and performances, it further gets conclusions.

The paper takes youth basketball reserve personnel training mode as research objects, it analyzes reserve personnel training mode influence factors, utilizes analytic hierarchy process to establish AHP model, and further gets conclusion that training mode of combination of sports and education is a mode that most suitable to Chinese youth basketball reserve personnel training, and meanwhile we also should encourage youth club and reserve personnel training base's training modes application.

\section{CONFLICT OF INTEREST}

The author confirms that this article content has no conflict of interest.

\section{ACKNOWLEDGEMENTS}

Declared none.

\section{REFERENCES}

[1] S. F. Huang, "Research on chinese men's basketball team's preparation against europe and american teams in the London olympic games", China Sport Science and Technology, vol. 48, no. 2, pp. 2934, 2012 .

[2] Y. Qinghui, and D. Fei, "The research on correlation between technical statistic and final place of men's basketball match", China Sport Science and Technology, vol. 35, no. 12, 1999.

[3] Z. Daliang, "The technical analysis on chinese basketball association and italian lega basket serie a based on gray system and other mathematical methods", Sport Science And Technology, vol. 28, no. 1, pp. 32-35, 2007.

L. Hui-lin, "Correlative analysis on technical statistics and competition result of our man's national basketball team", China Sport Science and Technology, vol. 43, no. 4, pp. 72-76, 2007.

[5] Y. Peng-fei, L. Jian-qin, and Y. Zhi-hua, "Analysis of movement laws of factors leading to victory in basketball matches", Journal of Wuhan Institute of Physical Education, vol. 39, no. 10, pp. 82-85, 2005 .

[6] W. Jianchuan, "Seek the countermeasure and the margin of the technique of chinese men basketball team from the 28th olympic games", Sport Science And Technology, vol. 27, no. 2, pp. 31-33, 2006.

[7] Z. Hui, and L. Dianyi, "Correlation between ball possession in different areas and victory or defeat in the 18th football world cup", Journal of Shenyang Sport University, vol. 28, no. 1, pp. 106-109, 2009

[8] D. Fei, "An analysis of the 3-point shot", Journal of Physical Education, vol. 10, no. 2, pp. 128-131, 2003.

[9] G. Lei, amd L. Jun, "A research on the relationship between the technical indicators and the net scores in CBA regular games held 
during the 03-04 season", Journal of Capital College of Physical Education, vol. 17, no. 1, pp. 84-86, 2005.
[10] L. Rizhong, "On CBA league match's trend based on the technical statistical analysis of the regular season in 2006- 2007 seasons", Sport Science And Technology, vol. 28, no. 4, pp. 45-49, 2007.

Received: June 10, 2015

Revised: July 29, 2015

Accepted: August 15, 2015

(C) Yongqiang Li; Licensee Bentham Open.

This is an open access article licensed under the terms of the (https://creativecommons.org/licenses/by/4.0/legalcode), which permits unrestricted, noncommercial use, distribution and reproduction in any medium, provided the work is properly cited. 